\title{
Fluorescence On/Off Switching in Polymers Bearing Diarylethene and Fluorene in Their Side Chains
}

Tatsumoto Nakahama, Daichi Kitagawa, Hikaru Sotome, Syoji Ito, Hiroshi Miyasaka, Seiya Kobatake

\begin{tabular}{|c|l|}
\hline Citation & The Journal of Physical Chemistry C, 121 (11); 6272-6281 \\
\hline Issue Date & $2017-03$ \\
\hline Type & Journal Article \\
\hline Textversion & author \\
\hline $\begin{array}{c}\text { Supporting } \\
\text { Information }\end{array}$ & $\begin{array}{l}\text { The Supporting Information is available free of charge on the ACS Publications } \\
\text { website at https://doi.org/10.1021/acs.jpcc.6b12819. }\end{array}$ \\
\hline Rights & $\begin{array}{l}\text { This document is the Accepted Manuscript version of a Published Work that appeared } \\
\text { in final form in The Journal of Physical Chemistry C, copyright } @ \text { American Chemical } \\
\text { Society after peer review and technical editing by the publisher. To access the final } \\
\text { edited and published work see https://doi.org/10.1021/acs.jpcc.6b12819 }\end{array}$ \\
\hline DOI & \begin{tabular}{l}
$10.1021 / a c s . j p c c .6 b 12819$ \\
\hline
\end{tabular} \\
\hline
\end{tabular}

Self-Archiving by Author(s)

Placed on: Osaka City University

Tatsumoto Nakahama, Daichi Kitagawa, Hikaru Sotome, Syoji Ito, Hiroshi Miyasaka, and Seiya Kobatake. Fluorescence On/Off Switching in Polymers Bearing Diarylethene and Fluorene in Their Side Chains. The Journal of Physical Chemistry C 2017121 (11), 6272-6281

DOI: 10.1021/acs.jpcc.6b12819 


\section{Fluorescence On/Off Switching in Polymers Bearing Diarylethene and Fluorene in Their Side Chains}

Tatsumoto Nakahama, ${ }^{\dagger}$ Daichi Kitagawa, ${ }^{\dagger}$ Hikaru Sotome, ${ }^{\ddagger}$ Syoji Ito,${ }^{\ddagger}$ Hiroshi Miyasaka, ${ }^{*}, \vec{\ddagger}$ and Seiya Kobatake, ${ }^{* \dagger}$

†Department of Applied Chemistry, Graduate School of Engineering, Osaka City University, 3-3-138 Sugimoto, Sumiyoshi-ku, Osaka 558-8585, Japan

E-mail: kobatake@a-chem.eng.osaka-cu.ac.jp

Division of Frontier Materials Science and Center for Promotion of Advanced Interdisciplinary

Research, Graduate School of Engineering Science, Osaka University, Toyonaka, Osaka 560-8531, Japan.

E-mail: miyasaka@chem.es.osaka-u.ac.jp 
ABSTRACT: A diarylethene-fluorene dyad connected by an ester bond (DE-FL) and random and alternative copolymers with diarylethene and fluorene moieties in their side chains $\left(\mathbf{p o l y}\left(\mathbf{D E} \mathbf{1}_{x}-\boldsymbol{c o}-\mathbf{F L} \mathbf{1}_{y}\right)\right.$ and poly(DE1-alt-FL2)) were synthesized, and their fluorescence on/off switching properties were investigated. All compounds exhibited reversible photochromism and fluorescence on/off switching in a solution upon alternating irradiation with ultraviolet (UV) and visible light. Although the fluorescence intensity of DE-FL linearly decreased with increasing photocyclization conversion of the diarylethene, the fluorescence intensity of $\operatorname{poly}\left(\mathbf{D E} 1_{x}-\mathbf{c o}-\mathbf{F L 1} \mathbf{1}_{y}\right)$ at the same molar fraction of diarylethene/fluorene significantly decreased with photocyclization conversion. Moreover, the fluorescence intensity of the polymers in the photostationary state was much lower than that of DE-FL. These results indicate that the fluorescence on/off switching properties of the polymers were improved by introducing diarylethene and fluorene moieties into their side chains. Moreover, it was revealed that the monomer sequences and the molar fractions of the diarylethene and fluorene moieties affected the fluorescence on/off switching properties of the copolymers. 


\section{Introduction}

Organic fluorescent materials have played an important role in various research fields, such as optoelectronics, ${ }^{1-3}$ bioimaging, ${ }^{4}$ and microanalysis. ${ }^{5}$ In particular, fluorescence-switchable molecules are widely studied and have potential applications in sensing materials, ${ }^{4-7}$ bioimaging materials for superresolution microscopy, ${ }^{8-10}$ and single-molecule memory materials ${ }^{11-16}$ because their fluorescence intensities and/or colors show sensitive changes in response to various external stimuli. Green fluorescent protein, carbocyanine dye, and photochromic molecules have been used as fluorescence-switchable materials. ${ }^{17}$ Recently, the fluorescence on/off switching of various photochromic diarylethenes has been reported. ${ }^{18,19}$ Diarylethenes undergo thermally irreversible photoisomerization between a colorless openring form and a colored closed-ring form upon alternating irradiation with ultraviolet (UV) and visible light; they show excellent performance, with high thermal stabilities, high photocyclization quantum yields, and high fatigue-resistant properties compared to other photochromic compounds. ${ }^{18,19}$ Diarylethenes linked to fluorophores exhibit fluorescence on/off switching upon alternating irradiation with UV and visible light. When diarylethenes are in their open-ring forms, the fluorophores exhibit fluorescence. When diarylethenes are converted to their closed-ring forms, the fluorescence is quenched by an energy transfer from the fluorophore moiety to the diarylethene closed-ring form. ${ }^{20,21}$ Fluorescenceswitchable diarylethenes exhibit properties, such as high fluorescence on/off contrast and rapid switching speed, which are desirable for applications in the field of optoelectronics and bioimaging. ${ }^{22}$ 
When the photocyclization conversion of diarylethenes linked to fluorophores does not reach $100 \%$ at the photostationary state (PSS), residual fluorescence occurs, which results in low fluorescence on/off contrast. To improve their fluorescence on/off contrast, molecules bearing one fluorophore and multiple diarylethenes have been reported. Bis(phenylethynyl)anthracene, ${ }^{23}$ porphyrin, ${ }^{24}$ and perylenediimide ${ }^{25}$ linked to multiple diarylethenes has been investigated for their fluorescence on/off switching properties. In particular, Zhu and co-workers reported that a perylenemonoimide dyad modified with triple diarylethenes exhibited a high fluorescence on/off switching speed; its fluorescence on/off contrast is the highest reported to date. ${ }^{22}$ Moreover, aggregates such as silica nanoparticles, ${ }^{26}$ organic nanoparticles, ${ }^{27}$ and polymers ${ }^{28-31}$ have been proposed as alternative approaches to improve fluorescence on/off switching properties. Recently, Métivier and co-workers reported that fluorescent photochromic organic nanoparticles prepared by a reprecipitation method exhibited bright red emission, complete on/off contrast with full reversibility, and excellent fatigue resistance. ${ }^{27}$

Among them, Akagi and co-workers reported a series of photoresponsive and full-colored fluorescent conjugated copolymers introduced diarylethene to their side chains, ${ }^{28}$ and demonstrated white fluorescence on/off switching by mixing the red, green, and blue fluorescent conjugated polymer nanoparticles in the appropriate ratio. ${ }^{29}$ Additionally, super-resolution localization of water-soluble fluorescence photoswicthable polymers was enabled with sub-40 $\mathrm{nm}$ spatial resolution in imaging subcellular organelles. ${ }^{30}$ Thus, the fluorescence on/off switchable diarylethene polymers are of great interest for the applications described above. However, there is few report on the effect of polymer 
structures such as a monomer sequence for the fluorescence on/off switching properties, such as the fluorescence on/off contrast and switching speed, although various systems of polymers containing diarylethenes and fluorophores have been proposed for the applications described above. By clarifying this effect, it is expected to lead to the system bearing more efficient fluorescence on/off switching properties even if the same diarylethene and fluorophore moieties are used.

In this work, we have focused on developing molecules with efficient fluorescent on/off switching properties, such as high speed switching and high fluorescence on/off contrast; we proposed the introduction of diarylethene and fluorene derivatives into the side chains of polymers. First, a diarylethene-fluorene dyad (DE-FL) connected by an ester bond was synthesized, as shown in Scheme 1. Next, random and alternative copolymers bearing diarylethene and fluorene derivatives in their side chains (poly(DE1 $x$-co-FL1 $y)$ and poly(DE1-alt-FL2)) were synthesized to investigate the effects of the molar fractions of diarylethene and fluorene and the monomer sequence of the copolymers on their fluorescence on/off switching properties. 
(a)
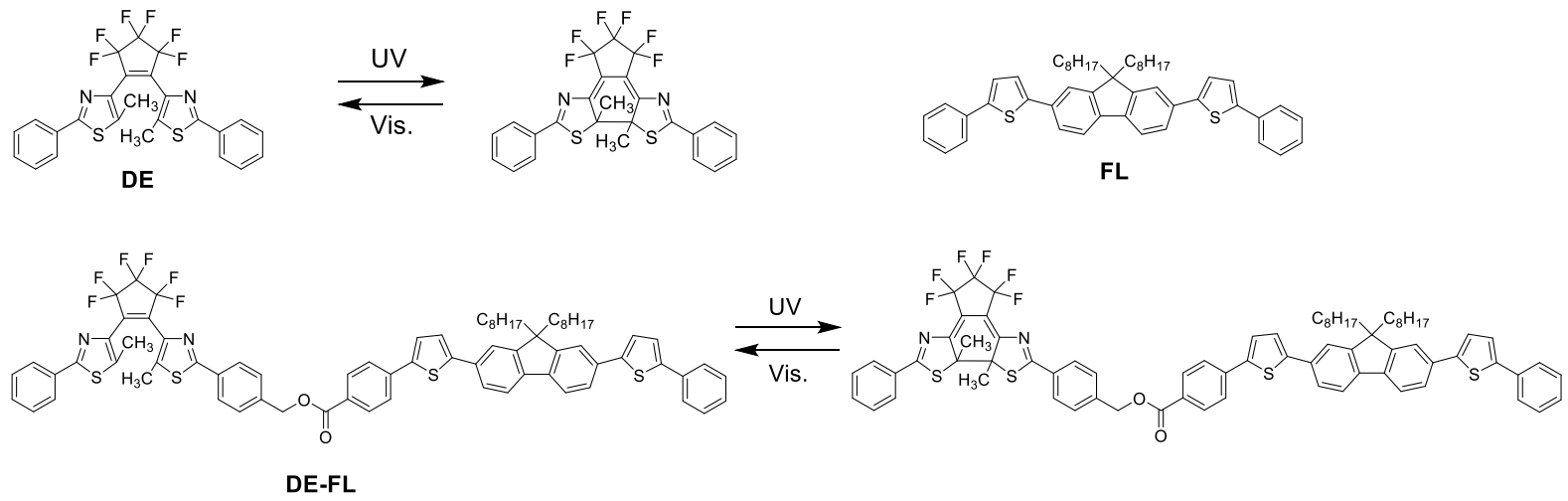

(b)
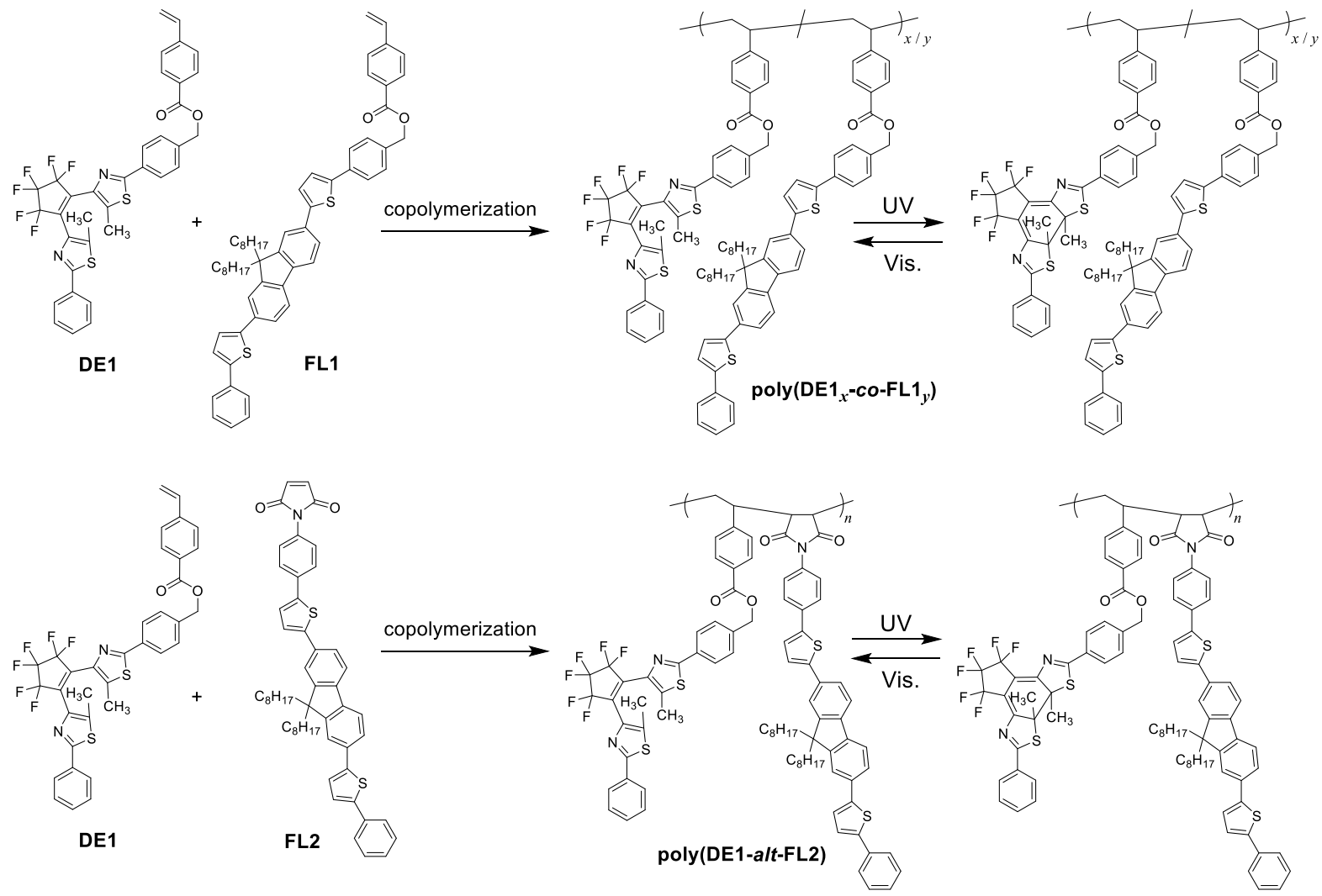

Scheme 1. (a) The molecular structures of diarylethene derivative (DE), fluorene derivative (FL), and diarylethene-fluorene dyad (DE-FL). (b) Synthesis and photochromic reaction of poly(DE1 $\left.1_{x}-c o-F L 1_{y}\right)$ and poly(DE1-alt-FL2). 


\section{Experimental Section}

General. ${ }^{1} \mathrm{H}$ NMR spectra were recorded on a Bruker AV-300N spectrometer at $300 \mathrm{MHz}$. Deuterated chloroform $\left(\mathrm{CDCl}_{3}\right)$ was used as the solvent, and tetramethylsilane (TMS) was used as an internal standard. Mass spectra were obtained using a Bruker FT-ICR/solariX mass spectrometer. Gel-permeation chromatography (GPC) was performed using a Tosoh 8000 series GPC system equipped with TSK-gel columns at $40{ }^{\circ} \mathrm{C}$ in tetrahydrofuran (THF) as the eluent. Standard polystyrenes were used as the calibration standard. Differential scanning calorimetry (DSC) was performed using a Hitachi DSC7000X instrument at a heating rate of $10^{\circ} \mathrm{C} \mathrm{min}^{-1}$. The glass transition temperature $\left(T_{\mathrm{g}}\right)$ was determined from an initial inflection point of temperature dependence on DSC. High-performance liquid chromatography (HPLC) was conducted using a Hitachi L-7150/L-2400 HPLC system equipped with a Kanto Chemical Mightysil Si60 column. Recycling preparative HPLC was conducted using a JAI LC-908 equipped with JAIGEL-1H and $2 \mathrm{H}$ columns using chloroform as the eluent. Absorption spectra were measured with a JASCO V-560 absorption spectrophotometer. Fluorescence spectra were measured with a Hitachi F-2700 fluorescence spectrophotometer.

Materials. 2,2'-Azobisisobutyronitrile (AIBN) was purified by recrystallization from methanol. Toluene and styrene (St) were purified by distillation. All other reagents were commercially available and were used without further purification. For preparing 1,2-bis(5-methyl-2-phenylthiazol-4yl)perfluorocyclopentene (DE), ${ }^{32,33}$ 2,7-bis(5-phenylthiophen-2-yl)-9,9-dioctylfluorene (FL), ${ }^{34}$ and 1-(5methyl-2-(4-(4-vinylbenzoyloxymethyl)phenyl)thiazol-4-yl)-2-(5-methyl-2-phenylthiazol-4- 
yl)perfluorocyclopentene (DE1), ${ }^{35}$ a method described in previous papers was used; as for 2-(5-(4-(4vinylbenzoyloxymethyl)phenyl)thiophen-2-yl)-7-(5-phenylthiophen-2-yl)-9,9-dioctylfluorene (FL1), $N$ 4-(5-(7-(5-phenylthiophen-2-yl)-9,9-dioctylfluoren-2-yl)thiophen-2-yl)phenylmaleimide (FL2), and 1(5-methyl-2-(4-(5-(7-(5-phenylthiophen-2-yl)-9,9-dioctylfluoren-2-yl)thiophen-2-

yl)benzoyloxymethyl)phenylthiazol-4-yl)-2-(5-methyl-2-phenylthiazol-4-yl)perfluorocyclopentene (DEFL), a description is given in the Supporting Information.

Polymerization. Radical polymerization was conducted in a sealed glass tube under vacuum. Monomer, AIBN, and toluene were placed in a glass tube. The tube was degassed by several freeze-pump-thaw cycles and sealed under vacuum. After polymerization for a prescribed time at $60{ }^{\circ} \mathrm{C}$, the resulting polymers were obtained by precipitation in methanol. The number- and weight-average molecular weights ( $M_{\mathrm{n}}$ and $M_{\mathrm{w}}$ ) of the polymers were determined by GPC calibrated with standard polystyrenes. The copolymer compositions were determined from the ${ }^{1} \mathrm{H}$ NMR spectra of the copolymers.

Photochemical Reaction. The photocyclization and cycloreversion quantum yields were determined in $n$-hexane relative to $\mathbf{D E}$, whose quantum yield has been previously determined $\left([\mathbf{D E}]=1.1 \times 10^{-5} \mathrm{M}\right.$ and $[$ DE-FL $\left.]=7.0 \times 10^{-6} \mathrm{M}\right) .{ }^{36}$ Photoirradiation was conducted using a $200 \mathrm{~W}$ mercury-xenon lamp (Moritex MUV-202) or a $300 \mathrm{~W}$ xenon lamp (Asahi Spectra MAX-301) as the light source. Monochromatic light was obtained by passing the light through a monochromator (Jobin Yvon H10 UV). Photocyclization conversions of DE-FL and the polymers were determined by ${ }^{1} \mathrm{H}$ NMR spectroscopy and absorption spectroscopic analysis. 
Fluorescence Quantum Yield. All measurements performed in solution were conducted with an optical density of approximately 0.1 at the excitation wavelength in 1-cm path length quartz cells at room temperature (298 K). All samples in a solution were deaerated by bubbling with argon gas for 5 min before the measurements. The fluorescence quantum yields $\left(\Phi_{\mathrm{f}}\right)$ were determined from the integrated intensity in the fluorescence spectrum of a measurement sample relative to that of a reference solution using eq. 1.37

$$
\Phi_{\mathrm{f}}=\Phi_{\mathrm{f}, \mathrm{ref}} \times \frac{A_{\mathrm{ref}}}{A} \times \frac{I_{\mathrm{ref}}}{I} \times \frac{F}{F_{\text {ref }}} \times \frac{n^{2}}{n_{\text {ref }}^{2}}
$$

where $A$ and $A_{\text {ref }}$ are the optical densities of the solutions at the excitation wavelength, $I$ and $I_{\text {ref }}$ are the excitation light intensities at the excitation wavelength, $F$ and $F_{\text {ref }}$ are the integrated intensities of the corrected fluorescence spectra, and $n$ and $n_{\text {ref }}$ are the refractive indices of the solvents used for the sample solution and a standard reference solution, respectively. Coumarin $102\left(\Phi_{\mathrm{f}}=0.76\right.$ in ethanol excited at $390 \mathrm{~nm})$ and Coumarin $153\left(\Phi_{\mathrm{f}}=0.54\right.$ in ethanol excited at $\left.390 \mathrm{~nm}\right)$ were used as standard references. ${ }^{38}$ The $\Phi_{\mathrm{f}}$ value was determined as the average of the values obtained using two standard references, and the relative experimental error was estimated to be less than $10 \%$.

Fluorescence Lifetime. Fluorescent dynamics of polymers with fluorene and diarylethene units were measured by means of time-correlated single-photon-counting (TCSPC) method. The experimental setup of our TCSPC system was described in the previous report. ${ }^{39}$ Briefly, the output of a Ti:Sapphire laser (Spectra-Physics, Tsunami, $800 \mathrm{~nm}, 1.8 \mathrm{~W}, 70 \mathrm{fs}, 80 \mathrm{MHz}$ ) was divided into two portions. The small portion was detected by a photodiode as a starting signal of TCSPC measurements. The remaining major 
portion was converted into the second harmonics $(400 \mathrm{~nm})$ using a type I barium borate (BBO) crystal and then used for the excitation of the sample. The repetition rate was reduced to $8 \mathrm{MHz}$ by using an electro-optic modulator (Conoptics, Model 350). The excitation power at the sample position was typically $16 \mu \mathrm{W}(8 \mathrm{MHz})$. Polarization of the excitation pulses was set to the magic angle with respect to that of the fluorescence detection by using a film polarizer and Babinet-Soleil compensator. A monochromator (Princeton Instruments, Acton SP-2150) was placed before the photomultiplier-tube (Hamamatsu Photonics, R3809U-50) equipped with combination of a pre-amplifier (Hamamatsu Photonics, C5594) and a TCSPC module (PicoQuant, PicoHarp 300). Sample solutions were put in 1-cm quartz cells. Typical response time of the system was ca. 40-ps fwhm, which was determined by the scattering signal of the colloidal solution. 


\section{Results and Discussion}

Molecular Design. DE and FL were employed as the photochromic and fluorophore units of the diarylethene-fluorene dyad and copolymers. DE is a diarylethene derivative, and both its open- and closed-ring forms have high thermal stability. FL shows blue fluorescence with high $\Phi_{\mathrm{f}}\left(\Phi_{\mathrm{f}}=0.69\right)$. Because the fluorescence on/off switching in this work is based on the Förster resonance energy transfer (FRET) from the fluorophore to the diarylethene closed-ring form, an overlap between the absorption spectrum of the diarylethene closed-ring form and the fluorescence spectrum of the fluorophore is required to quench the excited energy of the fluorophore with high efficiency. As shown in Figure 1, the fluorescence spectrum of FL properly overlaps the absorption spectrum of the closed-ring form of DE. Therefore, the fluorescence of FL is expected to be quenched when DE isomerizes from the open-ring form to the closed-ring form. Contrastingly, when DE is in the open-ring form, fluorescence quenching does not occur because the excited state energy level of DE is higher than that of FL. 


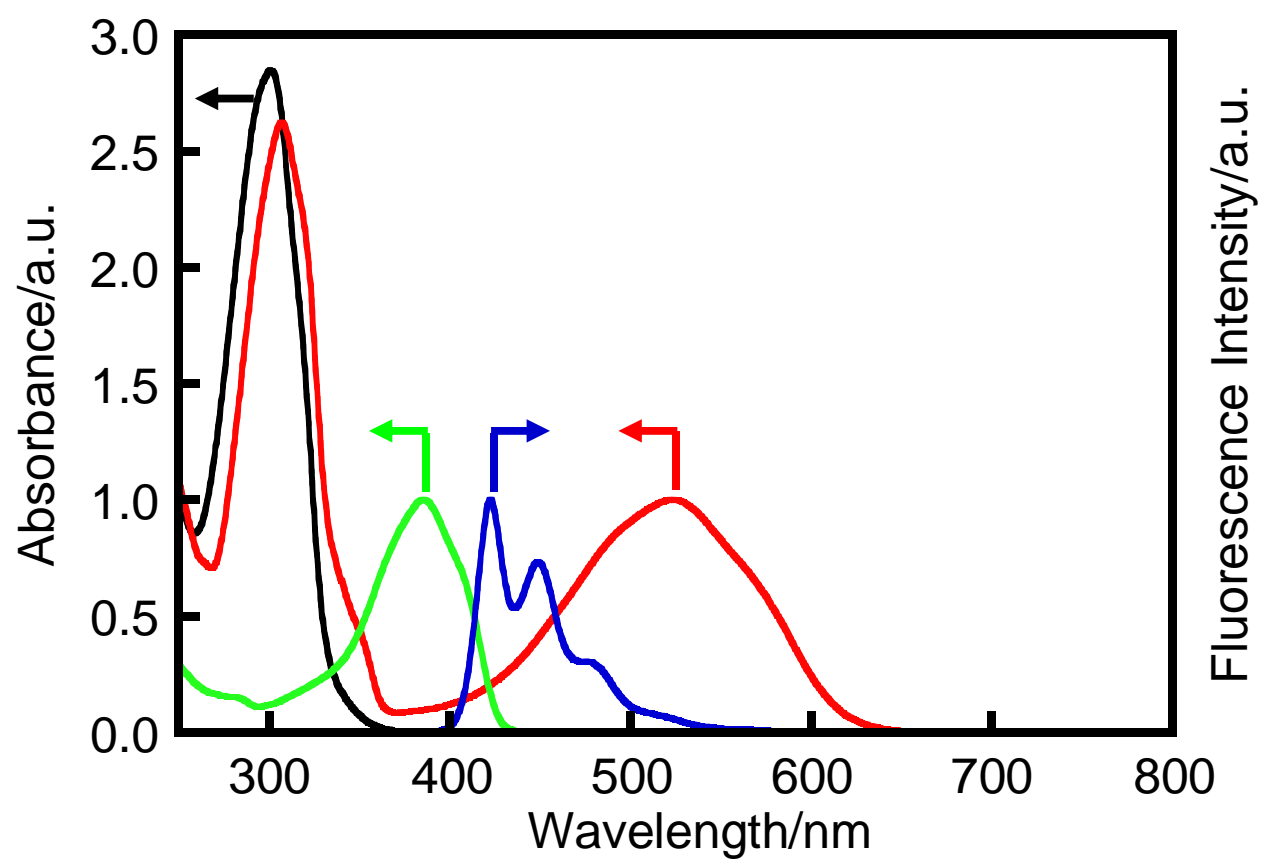

Figure 1. Normalized absorption spectra of the open-ring form (black line) and the photostationary solution upon irradiation with $313 \mathrm{~nm}$ light (red line) of DE in $n$-hexane, and normalized absorption spectrum (green line) and fluorescence spectrum under excitation at $366 \mathrm{~nm}$ (blue line) of FL in $n$-hexane.

In DE-FL, DE is covalently connected with FL through an ester spacer. St and maleimide monomers connected with FL (FL1 and FL2) were synthesized. Random copolymers bearing DE and FL in their

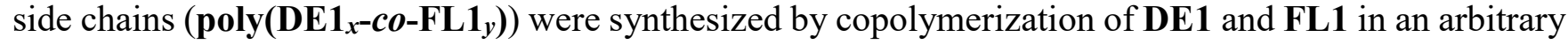
ratio, where $x$ and $y$ are the molar fractions of DE1 and FL1 in the copolymer, respectively. In addition, alternative copolymers (poly(DE1-alt-FL2)) were also synthesized by copolymerization of DE1 and FL2 with the same molar fractions. Because St and $N$-phenylmaleimide show a charge-transfer complex in the copolymerization process due to their electron-donating and electron-accepting characters, respectively, this copolymerization process leads to alternative copolymers with low monomer reactivity ratios $\left(r_{1}<<\right.$ 
0.1 and $\left.r_{2}<<0.1\right) .{ }^{40}$ It is expected that the fluorescence on/off switching properties of the polymers will be superior to those of DE-FL because a large number of fluorophores are quenched by a single closedring diarylethene in the polymer.

Polymerization. Table 1 shows the polymerization conditions, yields, $M_{\mathrm{n}}, M_{\mathrm{w}} / M_{\mathrm{n}}$, and $T_{\mathrm{g}}$ of the studied polymers. GPC elution curves and ${ }^{1} \mathrm{H}$ NMR spectra of the polymers are shown in Figures S1 and S2, respectively. The compositions of $\operatorname{poly}\left(\mathbf{D E} \mathbf{1}_{\boldsymbol{x}}\right.$-co-FL1 $\left.y\right)$ were estimated from absorption spectroscopic analysis. It was hypothesized that the absorption spectra of $\operatorname{poly}\left(\mathbf{D E} \mathbf{1}_{\boldsymbol{x}}\right.$-co-FL1 $\left.\mathbf{1}_{\boldsymbol{y}}\right)$ are consistent with the summation of a content of poly(DE1) and poly(FL1) in the composition of poly(DE1 $\left.\mathbf{1}_{x}-\operatorname{co}-\mathbf{F L 1} \mathbf{1}_{y}\right)$, as shown in Figure S3. The molar fraction of FL1 in all poly(DE1 $\mathbf{x}_{\boldsymbol{x}}$-co-FL1 $\left.\mathbf{1}_{\boldsymbol{y}}\right)$ were determined as shown in Table 1. Next, the composition of alternating copolymers was calculated from ${ }^{1} \mathrm{H}$ NMR spectroscopic analysis. The molar fraction of FL2 in poly(DE1-alt-FL2) and poly(St-alt-FL2) was estimated to be 48 and $49 \%$, respectively, by comparing the integral intensities of alkyl, $\mathrm{CH}_{2} \mathrm{OCO}$, and aromatic proton peaks. The composition curve for the copolymerization of FL1 with DE1 exhibited a linear relationship, as shown in Figure 2. Therefore, the composition of FL1 in the copolymers was almost the same as that in the feed. In addition, the yields, $M_{\mathrm{n}}$, and $M_{\mathrm{w}} / M_{\mathrm{n}}$ of the copolymers were similar. These results indicate that the introduction of DE and FL to the $p$-position of St did not affect the polymerization reactivity. The $T_{\mathrm{g}}$ values of poly(DE1) and poly(FL1) were determined to be $102{ }^{\circ} \mathrm{C}^{35}$ and $64{ }^{\circ} \mathrm{C}$ by DSC, respectively. The lower $T_{\mathrm{g}}$ of poly(FL1) is ascribed to the two octyl groups. The $T_{\mathrm{g}}$ values of poly(DE1 $x$-co-FL1 $\left.y\right)$ were determined to be $69-96{ }^{\circ} \mathrm{C}$ : these values decreased with increasing molar fraction of FL1 in the 
copolymer. Moreover, the compositions of FL2 in poly(DE1-alt-FL2) and poly(St-alt-FL2) were determined to be ca. $50 \mathrm{~mol} \%$. Thus, copolymers consisting of DE and $\mathbf{F L}$ in an arbitrary ratio could be fabricated. 
Table 1. Radical polymerization initiated with $\operatorname{AIBN}(0.020 \mathrm{M})$ in toluene for $10 \mathrm{~h}$ at $60{ }^{\circ} \mathrm{C}$ and characterization of the resulting polymers.

\begin{tabular}{|c|c|c|c|c|c|c|c|c|c|}
\hline Entry & $\begin{array}{c}{[\text { DE1 }]} \\
/ \mathrm{M}\end{array}$ & $\begin{array}{c}{[\mathbf{S t}]} \\
/ \mathrm{M}\end{array}$ & $\begin{array}{c}{[\mathbf{F L 1}]} \\
/ \mathrm{M}\end{array}$ & $\begin{array}{c}{[\mathbf{F L 2}]} \\
/ \mathrm{M}\end{array}$ & $\begin{array}{l}\text { Yield } \\
/ \%\end{array}$ & $M_{\mathrm{n}}$ & $M_{\mathrm{w}} / M_{\mathrm{n}}$ & $\begin{array}{c}\text { Molar fraction } \\
\text { of } \mathbf{F L} / \mathrm{mol}^{\mathrm{a}}{ }^{\mathrm{a}}\end{array}$ & $\begin{array}{c}T_{\mathrm{g}} \\
{ }^{\circ} \mathrm{C}\end{array}$ \\
\hline $1^{\mathrm{b}}$ & 0.37 & - & 0 & - & 79 & 41900 & 2.24 & 0 & 102 \\
\hline 2 & 0.38 & - & 0.062 & - & 66 & 43500 & 2.28 & $12^{\mathrm{d}}$ & 96 \\
\hline 3 & 0.31 & - & 0.12 & - & 62 & 43500 & 2.19 & $25^{\mathrm{d}}$ & 90 \\
\hline 4 & 0.19 & - & 0.19 & - & $-^{c}$ & 41100 & 2.77 & $52^{\mathrm{d}}$ & 81 \\
\hline 5 & 0.12 & - & 0.25 & - & 77 & 42900 & 2.40 & $65^{\mathrm{d}}$ & 74 \\
\hline 6 & 0.062 & - & 0.31 & - & 76 & 41900 & 2.92 & $86^{\mathrm{d}}$ & 71 \\
\hline 7 & 0.034 & - & 0.34 & - & 77 & 49700 & 2.71 & $90^{\mathrm{d}}$ & 69 \\
\hline 8 & 0 & - & 0.37 & - & 64 & 57200 & 2.83 & 100 & 64 \\
\hline 9 & 0.19 & - & - & 0.19 & 85 & 53400 & 3.00 & $48^{\mathrm{e}}$ & 78 \\
\hline 10 & - & 0.19 & - & 0.19 & 79 & 61100 & 3.06 & $49^{\mathrm{e}}$ & 60 \\
\hline
\end{tabular}

${ }^{a}$ Molar fraction of FL1 or FL2 in the polymer.

${ }^{\mathrm{b}}$ Ref. 35 .

${ }^{\mathrm{c}}$ Not determined.

${ }^{\mathrm{d}}$ Determined by absorption spectroscopic analysis.

${ }^{\mathrm{e}}$ Determined by ${ }^{1} \mathrm{H}$ NMR spectroscopic analysis 


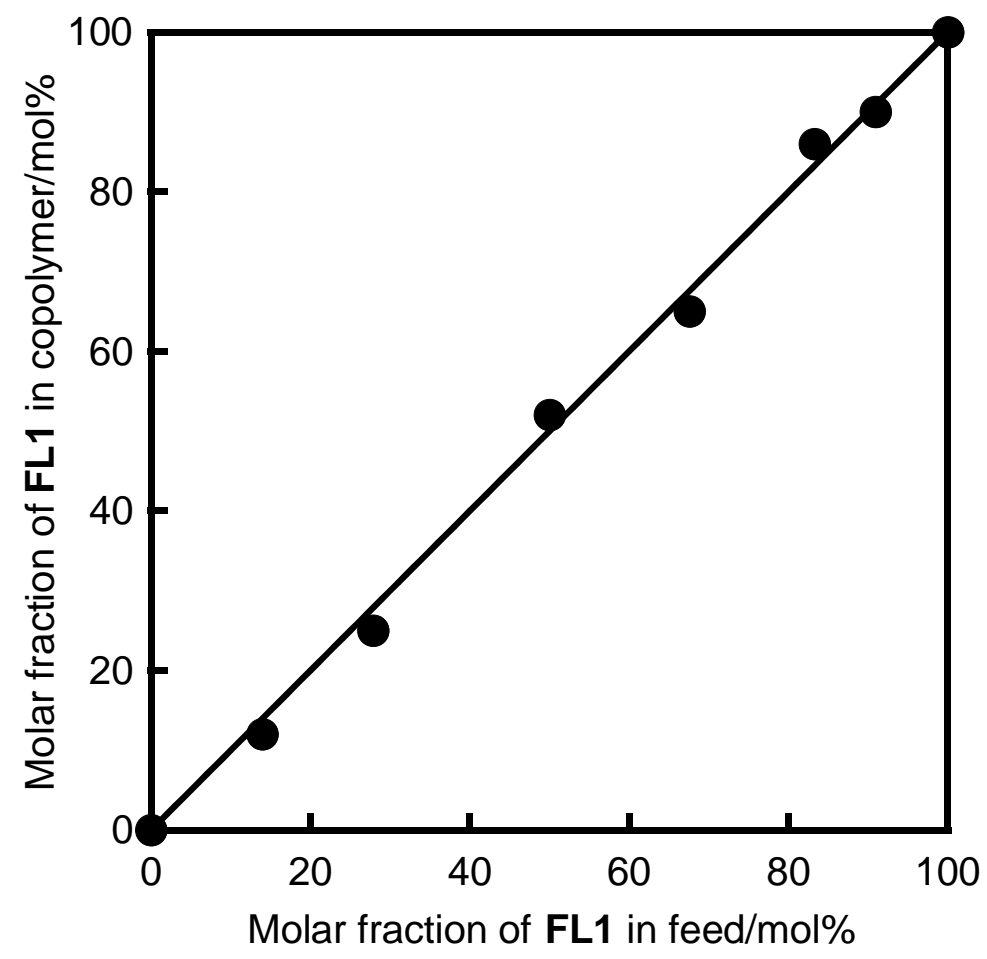

Figure 2. The composition curve for copolymerization of FL1 with DE1 in toluene at $60{ }^{\circ} \mathrm{C}$.

Photochromism. The optical properties of DE-FL and the polymers are summarized in Tables 2 and 3. Figure 3a-c shows the absorption spectral changes of DE-FL in $n$-hexane, poly(DE148-co-FL152) in THF, and poly(DE1-alt-FL2) in THF upon irradiation with $313 \mathrm{~nm}$ light. The absorption maximum wavelengths $\left(\lambda_{\mathrm{abs}}\right)$ were observed at 393,390 , and $390 \mathrm{~nm}\left(\varepsilon=79900,78500\right.$, and $\left.78200 \mathrm{M}^{-1} \mathrm{~cm}^{-1}\right)$ for DE-FL, poly(DE148-co-FL152), and poly(DE1-alt-FL2), respectively; these correspond to the band for the fluorene moiety. Upon irradiation with $313 \mathrm{~nm}$ light, the colorless solution became red, and new absorption bands appeared at 524, 534, and $534 \mathrm{~nm}$ for DE-FL, poly(DE1 48-co-FL152), and poly(DE1alt-FL2), respectively. The $\varepsilon$ values for the closed-ring forms of DE in DE-FL, poly(DE1 48-co-FL152), and poly(DE1-alt-FL2) were determined to be 15200,14300 , and $15500 \mathrm{M}^{-1} \mathrm{~cm}^{-1}$, respectively. $\lambda_{\text {abs }}$ and 
$\varepsilon$ of poly(DE1 $x-c o-F L 1 y)$ were almost constant regardless of the molar fraction of FL1 in the copolymer.

These spectral changes are ascribed to photoisomerization from the open- to the closed-ring forms. Upon irradiation with visible light (>500 nm), the solution colors and absorption spectra returned to their initial states. Thus, DE-FL and the copolymers exhibited reversible photochromic reactions upon alternating irradiation with UV and visible light. Their photocyclization conversions upon irradiation with $313 \mathrm{~nm}$ light were determined to be approximately $88 \%$.

Table 2. Optical properties of DE, FL, and DE-FL in $n$-hexane.

\begin{tabular}{cccccccc}
\hline Compound & $\lambda_{\mathrm{abs}} / \mathrm{nm}\left(\varepsilon / \mathrm{M}^{-1} \mathrm{~cm}^{-1}\right)$ & $\begin{array}{c}\text { Conv. } \\
/ \%\end{array}$ & $\Phi_{\mathrm{o} \rightarrow \mathrm{c}}$ & $\Phi_{\mathrm{c} \rightarrow \mathrm{o}}$ & $\begin{array}{c}\lambda_{\mathrm{flu}} \\
/ \mathrm{nm}\end{array}$ & $\Phi_{\mathrm{f}}$ & Contrast $^{\mathrm{a}}$ \\
\hline DE $^{\mathrm{b}}$ & $524(14900)^{\mathrm{c}}$ & 87 & 0.48 & 0.018 & - & - & - \\
FL $^{\mathrm{d}}$ & $383(80100)$ & - & - & - & $423,(449)$ & 0.69 & - \\
& & & & & & & \\
DE-FL & $393(79900)^{\mathrm{e}}, 524(15200)^{\mathrm{c}}$ & 88 & 0.25 & 0.016 & $436,(464)$ & 0.69 & 5.6 \\
& & & & & & & \\
\hline
\end{tabular}

${ }^{a}$ Contrast is defined as initial fluorescence intensity relative to fluorescence intensity at the PSS.

${ }^{\mathrm{b}} \operatorname{Ref} 32,33$.

${ }^{\mathrm{c}} \lambda_{\text {abs }}$ and $\varepsilon$ for the closed-ring form of $\mathbf{D E}$.

${ }^{\mathrm{d}} \operatorname{Ref} 34$.

${ }^{\mathrm{e}} \lambda_{\text {abs }}$ and $\varepsilon$ for $\mathbf{F L}$. 
Table 3. Optical properties of the studied polymers in THF.

\begin{tabular}{|c|c|c|c|c|c|}
\hline Polymer & $\lambda_{\mathrm{abs}} / \mathrm{nm}\left(\varepsilon / \mathrm{M}^{-1} \mathrm{~cm}^{-1}\right)$ & $\begin{array}{c}\text { Conv. } \\
/ \%\end{array}$ & $\begin{array}{c}\lambda_{\mathrm{flu}} \\
/ \mathrm{nm}\end{array}$ & $\Phi_{\mathrm{f}}$ & Contrast $^{\mathrm{a}}$ \\
\hline poly(DE1 $\left.1_{88-c o-F L 1} 12\right)$ & $391(78500)^{\mathrm{b}}, 534(13900)^{\mathrm{c}}$ & 87 & $433,(461)$ & 0.16 & 133 \\
\hline poly(DE1 $75-c o-F L 125)$ & $391(80700)^{\mathrm{b}}, 534(13200)^{\mathrm{c}}$ & 87 & $434,(463)$ & 0.13 & 106 \\
\hline poly(DE1 48-co-FL1 52) & $390(78500)^{\mathrm{b}}, 534(14300)^{\mathrm{c}}$ & 87 & $434,(462)$ & 0.15 & 71 \\
\hline poly(DE135-co-FL1 65$)$ & $390(78600)^{\mathrm{b}}, 534(14600)^{\mathrm{c}}$ & 87 & $434,(462)$ & 0.20 & 36 \\
\hline poly(DE1 14-co-FL186) & $389(78000)^{\mathrm{b}}, 534(14600)^{\mathrm{c}}$ & 88 & $434,(463)$ & 0.37 & 11 \\
\hline poly(DE1 10-co-FL190) & $389(80700)^{\mathrm{b}}, 534(14100)^{\mathrm{c}}$ & 88 & $435,(463)$ & 0.42 & 5.1 \\
\hline $\operatorname{poly}($ FL1) & $388(78800)^{b}$ & - & $436,(463)$ & 0.66 & - \\
\hline poly(DE1-alt-FL2) & $391(78200)^{\mathrm{b}}, 534(15500)^{\mathrm{c}}$ & 88 & $436,(464)$ & 0.21 & 76 \\
\hline poly(St-alt-FL2) & $390(79100)^{b}$ & - & $436,(463)$ & 0.69 & - \\
\hline
\end{tabular}

${ }^{\mathrm{a}}$ Contrast is defined as initial fluorescence intensity relative to fluorescence intensity at the PSS.

${ }^{\mathrm{b}} \lambda_{\mathrm{abs}}$ and $\varepsilon$ for the FL1 or FL2 unit in the polymers.

${ }^{\mathrm{c}} \lambda_{\mathrm{abs}}$ and $\varepsilon$ for the closed-ring form of the DE1 unit in the polymers. 

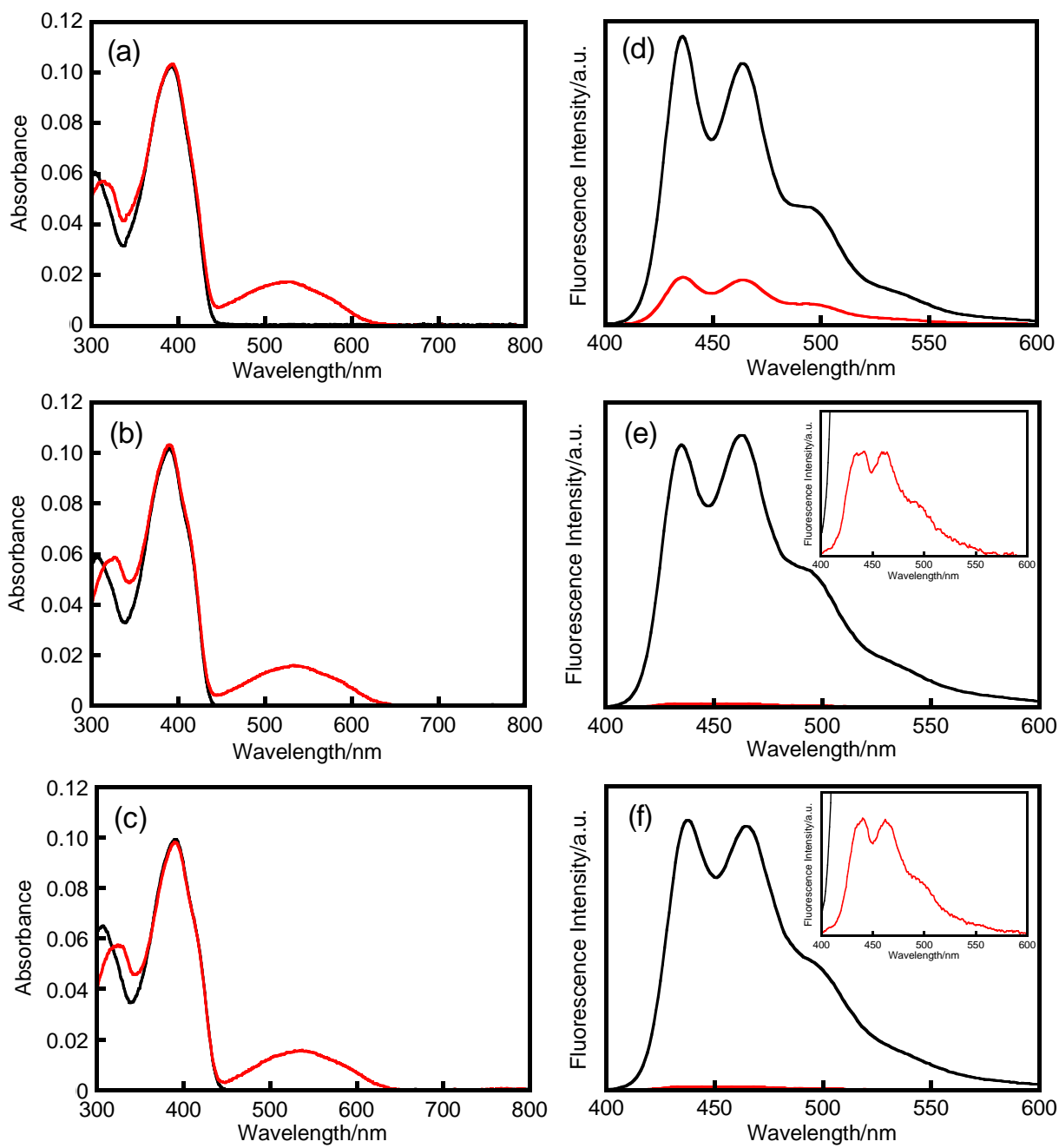

Figure 3. Absorption and fluorescence spectra of DE-FL in $n$-hexane (a,d), poly(DE148-co-FL152) in THF (b,e), and poly(DE1-alt-FL2) in THF (c,f) $\left(1.3 \times 10^{-6} \mathrm{M}\right.$ for DE or DE1 moiety): open-ring form (black line) and photostationary solution upon irradiation with $313 \mathrm{~nm}$ light (red line). The fluorescence spectra were recorded upon excitation at $390 \mathrm{~nm}$.

Fluorescence Properties. Figure $3 \mathrm{~d}-\mathrm{f}$ shows the fluorescence spectral changes of DE-FL in $n$-hexane, poly(DE148-co-FL152) in THF, and poly(DE1-alt-FL2) in THF upon excitation at $390 \mathrm{~nm}$. The fluorescence maximum wavelengths $\left(\lambda_{\text {flu }}\right)$ of the blue fluorescence for the fluorene moiety were observed at 436,434 , and $436 \mathrm{~nm}$, respectively. $\lambda_{\text {flu }}$ changed only slightly regardless of the molar fraction of FL1 
in poly $\left(\mathbf{D E} 1_{x}-\boldsymbol{c o}-\mathbf{F L 1} \mathbf{y}_{y}\right)$. The $\Phi_{\mathrm{f}}$ of DE-FL was determined to be 0.69 , which is similar to that of FL. The $\Phi_{\mathrm{f}}$ values for poly(DE148-co-FL152) and poly(DE1-alt-FL2) were determined to be 0.15 and 0.21 , respectively; these values are much smaller than those of DE-FL and FL. The $\Phi_{\mathrm{f}}$ values for $\operatorname{poly}\left(\mathbf{D E} \mathbf{1}_{x^{-}}\right.$ $\boldsymbol{c o}-\mathbf{F L 1}_{y}$ ) decreased from 0.42 to 0.13 with increasing molar fraction of $\mathbf{D E}$ in the copolymer. The low $\Phi_{\mathrm{f}}$ values of $\operatorname{poly}\left(\mathbf{D E 1}_{x}\right.$-co-FL1 $\left.1_{y}\right)$ and poly(DE1-alt-FL2) are due to the presence of the DE1 unit in the copolymers - this will be discussed in more detail later.

Fluorescence On/Off Switching. The fluorescence intensity gradually decreased upon irradiation with $313 \mathrm{~nm}$ light as shown in Figure 4a. This is ascribed to the energy transfer from the fluorene moiety to the diarylethene closed-ring form. Upon irradiation with visible light, the fluorescence intensity returned to its initial one. These results indicate that DE-FL and the copolymers demonstrate fluorescence on/off switching properties upon alternating irradiation with UV and visible light. Figure $4 \mathrm{~b}$ shows the relative fluorescence intensity $\left(F / F_{0}\right)$ related to the photocyclization conversion of the diarylethene. The $F / F_{0}$ value of DE-FL linearly decreased with increasing photocyclization conversion of the diarylethene. This result indicates that the fluorescence of the fluorene moiety in DE-FL was quenched by one diarylethene moiety in the closed-ring form. However, the residual fluorescence was observed at the PSS, although the fluorescence intensity of DE-FL decreased upon irradiation with UV light. The residual fluorescence is ascribed to two factors: one is the fluorescence of DE-FL in the open-ring form at the PSS, while the other is the fluorescence of DE-FL in the closed-ring form, which did not completely quench the fluorescence of the fluorene moiety. If the fluorescence of the fluorene moiety is completely quenched by 
the diarylethene closed-ring form, the slope of $F / F_{0}$ versus the photocyclization conversion should be $-0.01 / \%^{-1}$. The slope for DE-FL is $-0.0093 / \%^{-1}\left(r^{2}=0.99\right)$, which indicates that about $93 \%$ of the fluorescence of the fluorene moiety is quenched by the diarylethene close-ring form. Thus, the strong residual fluorescence and the linear fluorescence decay versus the photocyclization conversion indicate that DE-FL does not have efficient fluorescence on/off properties. Moreover, the fluorescence on/off switching properties of DE-FL in THF was also investigated as shown in Figure S4. The fluorescence spectra was red-shifted from $\lambda_{\text {flu }}=436 \mathrm{~nm}$ in $n$-hexane to $\lambda_{\text {flu }}=474 \mathrm{~nm}$ in THF, which is due to the electron-withdrawing effect of carbonyl group of fluorene moiety. The $\Phi_{\mathrm{f}}$ value in THF was determined to be 0.79 . Upon irradiation with UV and visible light, the fluorescence on/off switching was observed in THF as well as in $n$-hexane. The slope of the $F / F_{0}$ versus the photocyclization conversion is $-0.0099 / \%^{-1}$ $\left(r^{2}=0.99\right)$, which is slightly larger than that in $n$-hexane because the overlap integral between the absorption spectrum of the diarylethene closed-ring form and the fluorescence spectrum in THF is larger than that in $n$-hexane. To investigate the fluorescence on/off switching of DE-FL in more detail, the Förster distance $\left(R_{0}\right)$ and FRET efficiency $(E)$ were estimated as follows. The $R_{0}$ values of DE-FL in $n$ hexane and THF were determined to be 4.31 and $4.47 \mathrm{~nm}$, respectively, based on the Förster equation. ${ }^{41}$ Furthermore, the $E$ values of DE-FL in $n$-hexane and THF were calculated to be 99.0 and $99.2 \%$, respectively, when the distance between diarylethene and fluorene moieties was assumed to be $2.0 \mathrm{~nm}^{41}$ These results support that the slope in THF is slightly larger than that in $n$-hexane. 

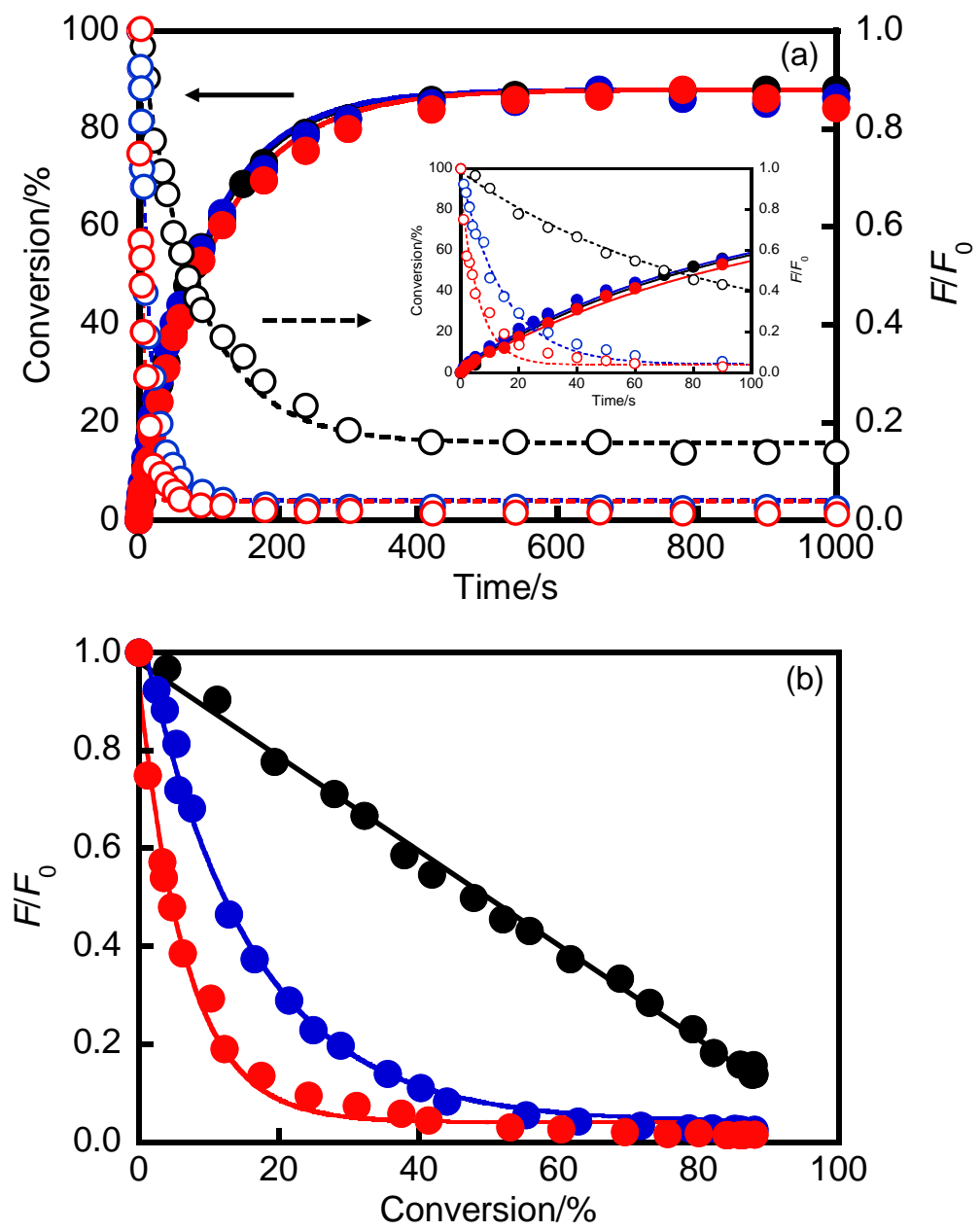

Figure 4. (a) Photocyclization conversion and normalized fluorescence intensity excited at $390 \mathrm{~nm}$ relative to irradiation time with $313 \mathrm{~nm}$ light $\left(0.24 \mathrm{~mW} \mathrm{~cm}^{-2}\right)$ of DE-FL in $n$-hexane $(\bigcirc$ and $\bigcirc)$, poly(DE148-co-FL152) in THF ( $\bigcirc$ and $\bigcirc$ ), and poly(DE1-alt-FL2) in THF ( $\bigcirc$ and $\bigcirc$ ). (b) Normalized fluorescence intensity excited at $390 \mathrm{~nm}$ relative to the photocyclization conversion of DE-FL in $n$-hexane ( $\bigcirc$ ), poly(DE1 48-co-FL152) in THF ( $\bigcirc$ ), and poly(DE1-alt-FL2) in THF ( $\bigcirc$ ).

Upon irradiation with $313 \mathrm{~nm}$ light $\left(0.24 \mathrm{~mW} \mathrm{~cm}^{-2}\right)$ for $60 \mathrm{~s}$, the fluorescence of poly(DE148-co-FL52) was almost quenched although the fluorescence intensity of DE-FL in $n$-hexane decreased upon irradiation for $400 \mathrm{~s}$. The photocyclization reaction speed of DE-FL and poly(DE148-co-FL52) versus UV irradiation time hardly changed. These results indicate that the fluorescence on/off switching of 
poly(DE1 48-co-FL152) was speedier than that of DE-FL. The fluorescence on/off contrast is defined as the value of the initial fluorescence intensity divided by the fluorescence intensity at the PSS. Contrasts for DE-FL and poly(DE148-co-FL152) were determined to be 5.6 and 71, respectively. The contrast for

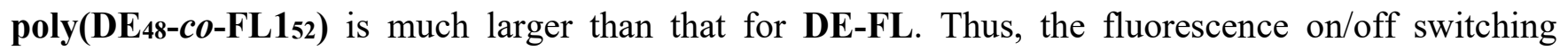

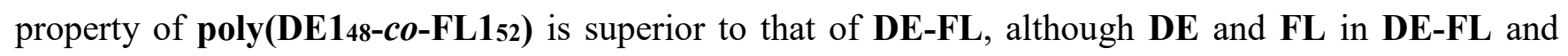

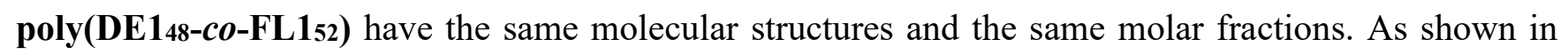
Figure $4 \mathrm{~b}$, the $F / F_{0}$ value of poly(DE1 48-co-FL1 $\left._{52}\right)$ largely decreased with increasing photocyclization conversion of the diarylethene. This is because a large number of fluorene moieties are quenched by a single closed-ring diarylethene in the copolymer. These results indicate that the introduction of DE and FL into the side chains of the polymers improved their fluorescence on/off switching properties.

Moreover, the fluorescence on/off switching of poly(DE1-alt-FL2) was speedier than that of poly(DE1 48-co-FL152) although their photocyclization reaction rates hardly changed. The $F / F_{0}$ value of poly(DE1-alt-FL2) significantly decreased with increasing photocyclization conversion of the diarylethene in comparison with that of poly(DE148-co-FL152). The number of fluorene moieties quenched by a single closed-ring diarylethene of poly(DE1 48-co-FL1 52) and poly(DE1-alt-FL2) is almost the same. Thus, the monomer sequence of the copolymer greatly affects its fluorescence on/off switching properties.

Figure 5 shows repeating cycles of the photochromic reactions and fluorescence on/off switching of poly(DE1-alt-FL2) upon alternating irradiation with UV and visible light, which could be repeated 10 
times without a significant decrease of the absorbance in their closed-ring form and the fluorescence intensity in their open-ring form.
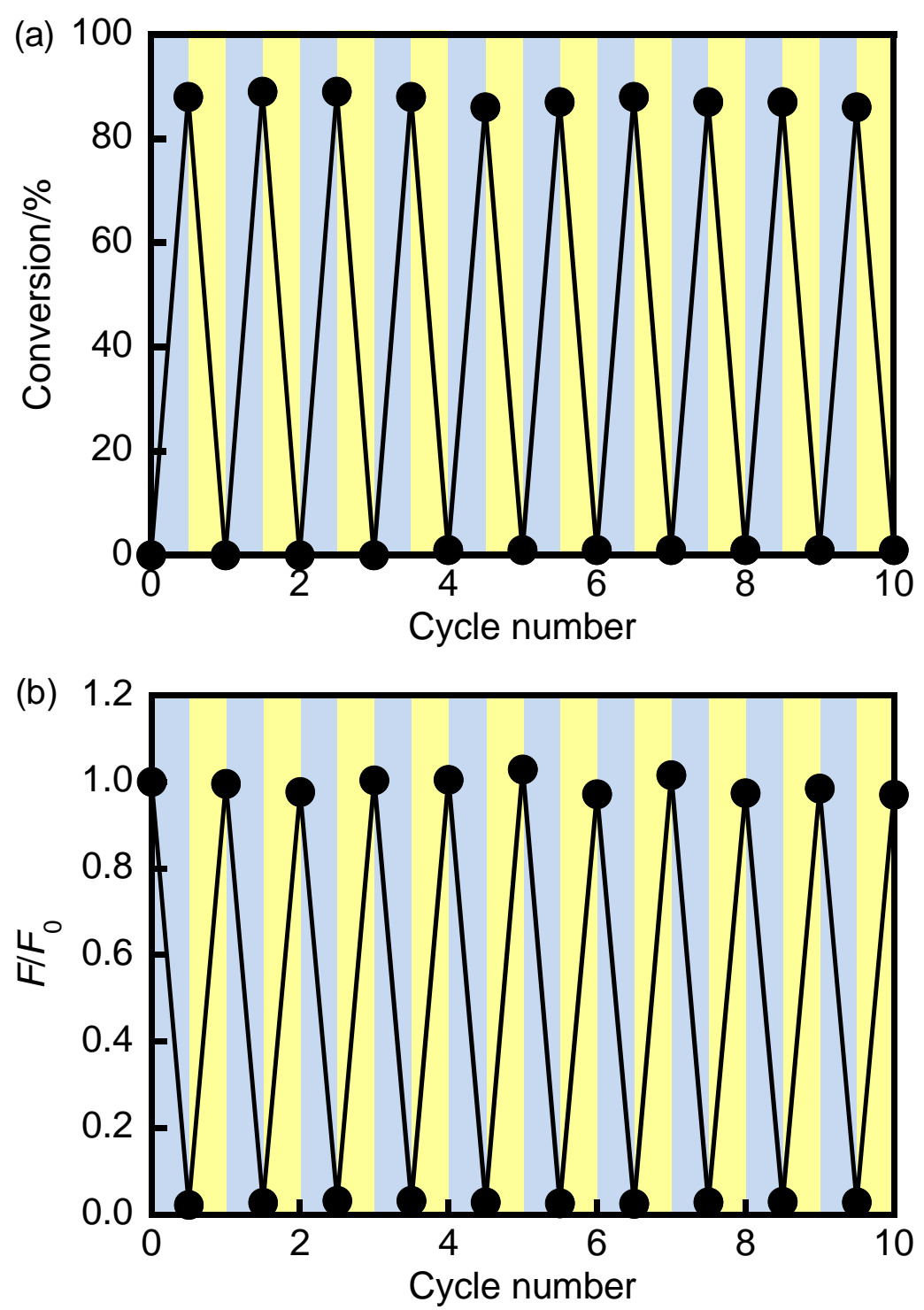

Figure 5. Reversible photochromic reactions (a) and fluorescence on/off switching (b) of poly(DE1-altFL2) in THF upon alternating irradiation with $313 \mathrm{~nm}$ light for $12 \min \left(0.23 \mathrm{~mW} \mathrm{~cm}{ }^{-2}\right.$, blue region) (a) and $60 \mathrm{~s}\left(0.22 \mathrm{~mW} \mathrm{~cm}{ }^{-2}\right.$, blue region) (b) and visible light for $3 \mathrm{~min}$ (>500 nm, yellow region). 
Next, the dependence of the fluorescence on/off switching properties on the molar fraction of DE1 and

FL1 in poly(DE1 $x$-co-FL1 $\left.y_{y}\right)$ was investigated. Figure S5 shows the absorption and fluorescence spectral changes of poly(DE1 $\left.1_{x}-c o-F L 1_{y}\right)$ with various molar fractions of FL1. The $F / F_{0}$ values for poly(DE1 $\mathbf{x}_{x}$-coFL1 $_{y}$ ) versus the photocyclization conversion are shown in Figure 6. All the copolymers showed fluorescence on/off switching upon irradiation with UV and visible light. The change in the $F / F_{0}$ value relative to the photoisomerization conversion decreased with increasing molar fraction of FL1 in the copolymer. The fluorescence on/off contrast for poly(DE1 10-co-FL190) was determined to be 5.1, and $30 \%$ of the initial fluorescence was observed as the residual fluorescence even at the PSS. These results are ascribed to the increase in the number of fluorene moieties outside the area where the diarylethene closed-ring form in the copolymer can quench their excited energies. On the other hand, the changes in the $F / F_{0}$ value versus the photocyclization conversion increased with decreasing molar fraction of FL1 in the copolymer. The contrast for poly(DE1 s8-co-FL1 $\left._{12}\right)$ with the smallest molar fraction of FL1 in this work was determined to be 133, and the fluorescence of poly(DE1 18-co-FL1 12) was almost quenched at the PSS. Poly(DE1 18-co-FL1 12) showed the most efficient fluorescence on/off switching properties among the poly(DE1 $\left.\mathbf{1}_{x}-\boldsymbol{c o}-\mathbf{F L} \mathbf{1}_{y}\right)$ polymers. These results revealed that the fluorescence on/off switching properties of $\operatorname{poly}\left(\mathbf{D E} \mathbf{1}_{x}-c o-\mathbf{F L} 1_{y}\right)$ improved as the molar fraction of FL1 decreased. 


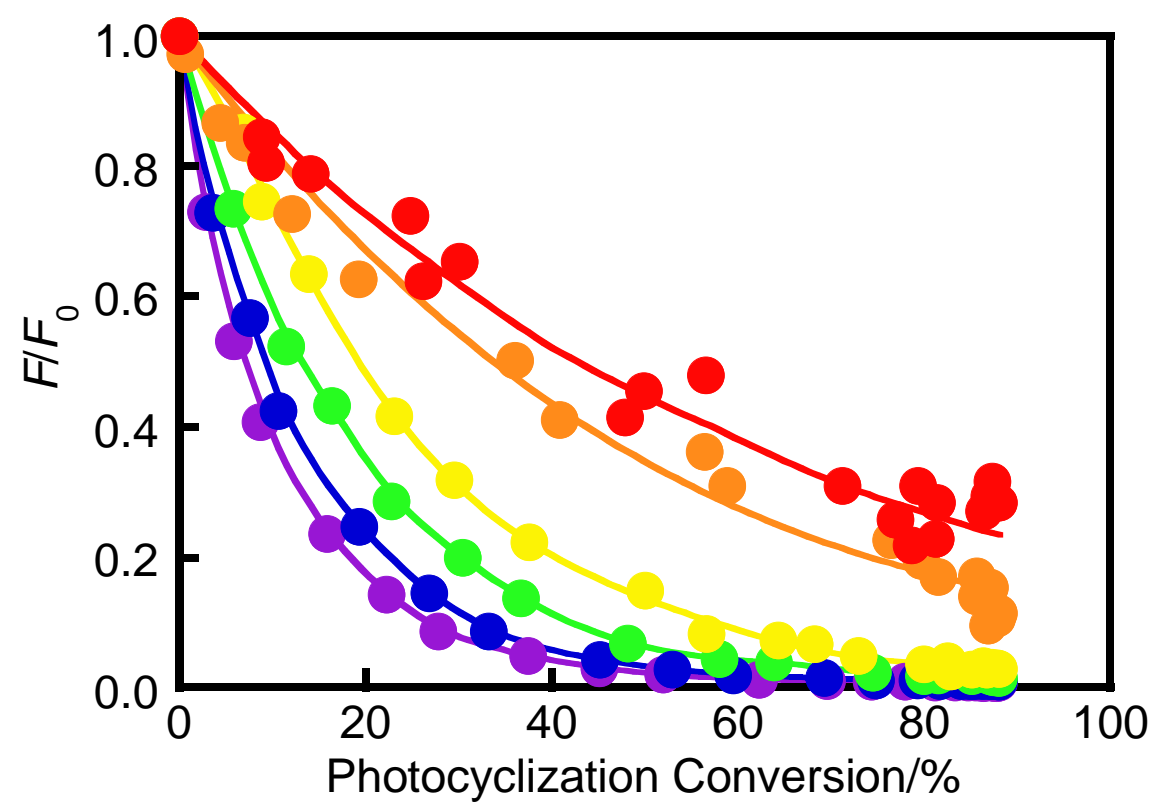

Figure 6. Normalized fluorescence intensity excited at $390 \mathrm{~nm}$ as a function of the photocyclization

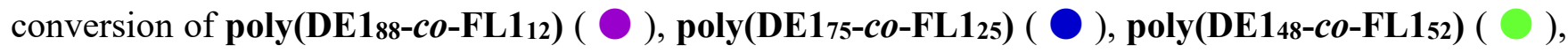
poly(DE135-co-FL165) ( $\odot$ ), poly(DE1 14-co-FL186) ( $\bigcirc)$, and poly(DE110-co-FL190) ( $\bigcirc)$ in THF (1.3$1.4 \times 10^{-6} \mathrm{M}$ for fluorene moiety).

Fluorescence Quantum Yield and Fluorescence Lifetime. As mentioned above, the $\Phi_{\mathrm{f}}$ values of $\operatorname{poly}\left(D E 1_{x}\right.$-co-FL1 $\left.y\right)$ and poly(DE1-alt-FL2) are lower than those of DE-FL and FL. The absorbance and fluorescence properties of poly(FL1) and poly(St-alt-FL2) in THF were investigated to reveal the reason for the decrease of $\Phi_{\mathrm{f}}$ (Figure S6). The $\Phi_{\mathrm{f}}$ values of poly(FL1) and poly(St-alt-FL2) were determined to be 0.66 and 0.69 , respectively. These values are almost the same as those of DE-FL and FL. This result reveals that introduction of the fluorene moiety into the side chains of the polymer only slightly affects its fluorescence properties; it also indicates that the lower $\Phi_{\mathrm{f}}$ values of poly(DE1 $\mathbf{1}_{\boldsymbol{x}}-\mathbf{c o}$ FL1 $y)$ and poly(DE1-alt-FL2) are not due to intermolecular interactions between the fluorene moieties. 
Next, the intermolecular interactions between the diarylethene open-ring form and the fluorene moiety were examined. There is a slight overlap between the absorption spectrum of poly(DE1) in the open-ring form and the fluorescence spectrum of poly(FL1) in THF (Figure S7), which indicates that an energy transfer from the fluorene moiety to the diarylethene open-ring form can occur. Moreover, it is considered that the energy transfer is enhanced in the copolymers because the fluorescence of multiple fluorene moieties is quenched by one diarylethene moiety in the open-ring form. Moreover, because the distance between diarylethene and fluorene moieties is short, other energy transfer process through the exchange interaction such as Dexter mechanism may contribute to some extent. As a result, the $\Phi_{\mathrm{f}}$ values of poly(DE1 $x_{x}$-co-FL1 $\left.1_{y}\right)$ and poly(DE1-alt-FL2) decreased due to the increase in the non-radiative energy transfer process by the intermolecular interactions between the diarylethene open-ring form and the fluorene moiety.

In order to further investigate the fluorescence properties of the copolymers, their fluorescence lifetimes were measured (Figure S8). The results are summarized in Table 4. FL showed $\tau$ of 0.75 ns with a single component. DE-FL showed $\tau$ of $0.89 \mathrm{~ns}$ accompanied with a rise component of $0.20 \mathrm{~ns}$. The component of ca. $0.8 \mathrm{~ns}$ is due to the fluorescence of the fluorene moiety. The rise component of ca. $0.2 \mathrm{~ns}$ may be due to an energy transfer from the diarylethene open-ring form at the excited state to the fluorene moiety. DE-FL at the photostationary state showed the same values as that in the open-ring form, while $\Phi_{\mathrm{f}}$ decreased at the PSS. This means that the energy transfer from the fluorene moiety at the excited state to the diarylethene closed-ring form is fast enough not to detect the fluorescent lifetime, and that the 
diarylethene closed-ring form efficiently quenches the fluorescence of the fluorene moiety. On the other hand, the studied polymers showed fluorescence lifetimes with multiple components; 0.10 (59\%), 0.43 (31\%), 1.1 (7\%), and $3.6 \mathrm{~ns}(2 \%)$ for poly(DE1 48-co-FL152) and 0.091 (61\%), 0.44 (27\%), $1.2(10 \%)$, and $3.5 \mathrm{~ns}(2 \%)$ for poly(DE1-alt-FL2) in the open-ring form in THF. Average fluorescence lifetimes ( $\left.\tau_{\text {ave }}\right)$ were calculated from these values according to $\tau_{\text {ave }}=\Sigma(\tau \times \%)$; they were determined to be $0.34 \mathrm{~ns}$

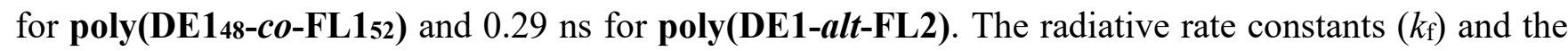
non-radiative rate constants $\left(k_{\mathrm{nr}}\right)$ were calculated from $\Phi_{\mathrm{f}}$ according to $\tau_{\mathrm{ave}}: k_{\mathrm{f}}=\Phi_{\mathrm{f}} / \tau_{\mathrm{ave}}$ and $k_{\mathrm{nr}}=(1-$ $\left.\Phi_{\mathrm{f}}\right) / \tau_{\text {ave. }}$. The $k_{\mathrm{f}}$ values were calculated to be $0.44 \times 10^{9}$ and $0.71 \times 10^{9} \mathrm{~s}^{-1}$, and the $k_{\mathrm{nr}}$ values were calculated to be $2.5 \times 10^{9}$ and $2.7 \times 10^{9} \mathrm{~s}^{-1}$ for poly(DE148-co-FL152) and poly(DE1-alt-FL2), respectively, in the open-ring form in THF. The same method was used to calculate $\tau_{\mathrm{ave}}, k_{\text {f, }}$ and $k_{\mathrm{nr}}$ for poly(FL1) and poly(St-alt-FL2). Two components for $\tau$ in both poly(FL1) and poly(St-alt-FL2) were observed, which may be ascribed to the difference in the conformation in the polymers. The $\tau_{1}$ values of

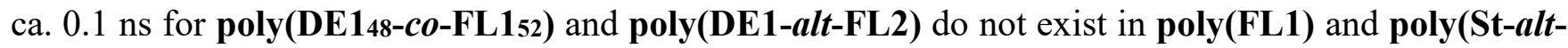
FL2), which correspond to the energy transfer from the fluorene moiety to the diarylethene open-ring form. This result supports the presence of the intermolecular interactions between the diarylethene open-

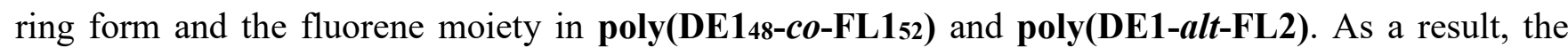
apparent $k_{\mathrm{nr}}$ values for poly(DE1 48-co-FL152) and poly(DE1-alt-FL2) are much larger than those for poly(FL1) and poly(St-alt-FL2). 
Table 4. Fluorescence lifetimes, fluorescence quantum yields, and radiative and non-radiative rate constants in THF.

\begin{tabular}{|c|c|c|c|c|c|c|c|c|c|}
\hline Compound & $\begin{array}{c}\tau_{1} \\
/ \mathrm{ns}\end{array}$ & $\begin{array}{c}\tau_{2} \\
/ \mathrm{ns}\end{array}$ & $\begin{array}{c}\tau_{3} \\
/ \mathrm{ns}\end{array}$ & $\begin{array}{c}\tau_{4} \\
/ \mathrm{ns}\end{array}$ & $\begin{array}{c}\tau_{\mathrm{ave}}{ }^{\mathrm{a}} \\
/ \mathrm{ns}\end{array}$ & $\chi^{2}$ & $\Phi_{\mathrm{f}}$ & $\begin{array}{c}k_{\mathrm{f}} \\
/ \mathrm{ns}^{-1}\end{array}$ & $\begin{array}{c}k_{\mathrm{nr}} \\
/ \mathrm{ns}^{-1} \\
\end{array}$ \\
\hline $\mathbf{F L}^{\mathrm{b}}$ & 0.75 & - & - & - & - & 1.06 & 0.69 & 0.92 & 0.42 \\
\hline DE-FL & $\begin{array}{c}0.22(17 \% \\
\text { rise })\end{array}$ & $0.89(83 \%)$ & - & - & 0.70 & 1.00 & 0.69 & 0.98 & 0.44 \\
\hline poly(DE1 $\left.{ }_{48}-c o-F L 1_{52}\right)$ & $0.10(59 \%)$ & $0.43(31 \%)$ & $1.1(7 \%)$ & $3.6(2 \%)$ & 0.34 & 1.06 & 0.15 & 0.44 & 2.49 \\
\hline poly(FL1) & $0.32(16 \%)$ & $1.1(84 \%)$ & - & - & 0.98 & 1.16 & 0.66 & 0.68 & 0.35 \\
\hline poly(DE1-alt-FL2) & $0.091(61 \%)$ & $0.44(27 \%)$ & $1.2(10 \%)$ & $3.5(2 \%)$ & 0.29 & 1.07 & 0.21 & 0.71 & 2.68 \\
\hline poly(St-alt-FL2) & $0.22(12 \%)$ & $1.0(88 \%)$ & - & - & 0.91 & 1.14 & 0.69 & 0.76 & 0.34 \\
\hline
\end{tabular}




\section{CONCLUSION}

We synthesized a diarylethene-fluorene dyad connected by an ester bond (DE-FL) and random and alternative copolymers bearing DE and FL in their side chains (poly(DE1 $\boldsymbol{x}_{\boldsymbol{x}}$-co-FL1 $\left.\mathbf{1}_{\boldsymbol{y}}\right)$ and poly(DE1-altFL2)) to develop materials with highly efficient fluorescence on/off switching properties. Although the fluorescence intensity of DE-FL linearly decreased with increasing photocyclization conversion of the diarylethene, the fluorescence intensities of the copolymers significantly decreased with increasing photocyclization conversion of the diarylethene because the fluorescence of many fluorene moieties was quenched by one closed-ring diarylethene moiety. In addition, the fluorescence intensity of poly(DE1alt-FL2) significantly decreased with increasing photocyclization conversion of the diarylethene in comparison with that of poly(DE148-co-FL152), which revealed that the monomer sequence affects the fluorescence on/off switching properties of the copolymers. Moreover, the fluorescence on/off switching properties, such as the switching speed and contrast, of $\operatorname{poly}\left(\mathbf{D E} \mathbf{1}_{x}-\operatorname{co}-\mathbf{F L} \mathbf{1}_{y}\right)$ were improved by decreasing molar fraction of FL1 in the copolymer. The $\Phi_{\mathrm{f}}$ values of the copolymers were smaller than those of DE-FL and FL. This is ascribed to the energy transfer from the fluorene moiety to the diarylethene moiety in the open-ring form. 


\section{ASSOCIATED CONTENT}

\section{Supporting Information}

Synthetic methods of monomers and Figures S1-S8 (PDF). This material is available free of charge via the Internet at http://pubs.acs.org.

\section{AUTHOR INFORMATION}

\section{Corresponding Author}

*E-mail: miyasaka@chem.es.osaka-u.ac.jp (H.M.).

*E-mail: kobatake@a-chem.eng.osaka-cu.ac.jp (S.K.).

\section{Notes}

The authors declare no competing financial interest.

\section{ACKNOWLEDGMENTS}

This work was partly supported by JSPS KAKENHI Grant Numbers JP26107002, JP26107013 in

Scientific Research on Innovative Areas "Photosynergetics", JP16H06505 in Scientific Research on Innovative Areas “Nano-Material Optical-Manipulation”, JP16K17896, JP26288009, JP16H03827, and JP15K13625. The authors also thank Osaka Gas Chemical Co., Ltd. and Nippon Zeon Co., Ltd. for providing chemicals. 


\section{References}

(1) Yang, X.; Zhou, G.; Wong, W.-Y. Functionalization of Phosphorescent Emitters and Their Host Materials by Main-Group Elements for Phosphorescent Organic Light-Emitting Devices. Chem. Soc. Rev. 2015, 44, 8484-8575.

(2) Scholz, S.; Kondakov, D.; Lüssem, B.; Leo, K. Degradation Mechanisms and Reactions in Organic Light-Emitting Devices. Chem. Rev. 2015, 115, 8449-8503.

(3) Shizu, K.; Uejima, M.; Nomura, H.; Sato, T.; Tanaka, K.; Kaji, H.; Adachi, C. Enhanced Electroluminescence from a Thermally Activated Delayed-Fluorescence Emitter by Suppressing Nonradiative Decay. Phys. Rev. Applied 2015, 3, 014001 (1-7).

(4) Stender, A. S.; Marchuk, K.; Liu, C.; Sander, S.; Meyer, M. W.; Smith, E. A.; Neupane, B.; Wang, G.; Li, J.; Cheng, J.-X. et al. Single Cell Optical Imaging and Spectroscopy. Chem. Rev. 2013, $113,2469-2527$.

(5) Roeffaers, M. B. J.; Sels, B. F.; Uji-i, H.; De Schryver, F. C. ; Jacobs, P. A. ; De Vos, D. E.; Hofkens, J. Spatially Resolved Observation of Crystal-Face-Dependent Catalysis by Single Turnover Counting. Nature, 2006, 439, 572-575.

(6) Pu, S.-Z.; Sun, Q.; Fan, C.-B.; Wang, R.-J.; Li, G. Recent Advances in Diarylethene-Based MultiResponsive Molecular Switches. J. Mater. Chem. C 2016, 4, 3075-3093. 
(7) Yang, Z.; Cao, J.; He, Y.; Yang, J. H.; Kim, T.; Peng, X.; Kim, J. S.; Macro-/Micro-EnvironmentSensitive Chemosensing and Biological Imaging. Chem. Soc. Rev. 2014, 43, 4563-4601.

(8) Betzig, E.; Patterson, G. H.; Sougrat, R.; Lindwasser, O. W.; Olenych, S.; Bonifacino, J. S.; Davidson, M. W.; Lippincott-Schwartz, J.; Hess, H. F. Imaging Intracellular Fluorescent Proteins at Nanometer Resolution. Science, 2006, 313, 1642-1645.

(9) Hess, S. T.; Girirajan, T. P. K.; Mason, M. D. Ultra-High Resolution Imaging by Fluorescence Photoactivation Localization Microscopy. J. Biophys. 2006, 91, 4258-4272.

(10) Sengupta, P.; van Engelenburg, S. B.; Lippincott-Schwartz, J.; Superresolution Imaging of Biological Systems Using Photoactivated Localization Microscopy. J. Chem. Rev. 2014, 114, 3189-3202.

(11) Fukaminato, T.; Kobatake, S.; Kawai, T.; Irie, M. Three-Dimensional Erasable Optical Memory Using a Photochromic Diarylethene Single Crystal as the Recording Medium. Proc. Jpn. Acad., Ser. B 2001, 77, 30-35.

(12) Corredor, C. C.; Huang, Z. -L.; Belfield, K. D. Two-Photon 3D Optical Data Storage via Fluorescence Modulation of an Efficient Fluorene Dye by a Photochromic Diarylethene. Adv. Mater. 2006, 18, 2910-2914. 
(13) Corredor, C. C.; Huang, Z.-L.; Belfield, K. D.; Morales, A. R. Bondar, M. V. Photochromic Polymer Composites for Two-Photon 3D Optical Data Storage. Chem. Mater. 2007, 19, $5165-5173$.

(14) Yun, C.; You, J.; Kim, J.; Huh, J.; Kim, E. Photochromic Fluorescence Switching from Diarylethenes and its Applications. J. Photochem. Photobiol. C 2009, 10, 111-129.

(15) Fukaminato, T.; Doi, T.; Tamaoki, N.; Okuno, K.; Ishibashi, Y.; Miyasaka, H.; Irie, M. SingleMolecule Fluorescence Photoswitching of a Diarylethene-Perylenebisimide Dyad: NonDestructive Fluorescence Readout. J. Am. Chem. Soc. 2011, 133, 4984-4990.

(16) Irie, M.; Fukaminato, T.; Sasaki, T.; Tamai, N.; Kawai, T. Organic Chemistry: a Digital Fluorescent Molecular Photoswitch. Nature 2002, 420, 759-760.

(17) Fukaminato, T. Single-Molecule Fluorescence Photoswitching: Design and Synthesis of Photoswitchable Fluorescent Molecules. J. Photochem. Photobiol. C 2011, 12, 177-208.

(18) Kobatake, S.; Irie, M. Single-Crystalline Photochromism of Diarylethenes. Bull. Chem. Soc. Jpn. 2004, 77, 195-210.

(19) Irie, M.; Fukaminato, T.; Matsuda, K.; Kobatake, S. Photochromism of Diarylethene Molecules and Crystals: Memories, Switches, and Actuators. Chem. Rev. 2014, 114, 12174-12277. 
(20) Giordano, L.; Jovin, T. M.; Irie, M.; Jares-Erijman, E. A. Diheteroarylethenes as Thermally Stable Photoswitchable Acceptors in Photochromic Fluorescence Resonance Energy Transfer (pcfret). $J$. Am. Chem. Soc. 2002, 124, 7481-7489.

(21) Métivier, R.; Badré, S.; Méallet-Renault, R.; Yu, P.; Pansu, R. B., Nakatani, K. Fluorescence Photoswitching in Polymer Matrix: Mutual Influence between Photochromic and Fluorescent Molecules by Energy Transfer Processes. J. Phys. Chem. C 2009, 113, 11916-11926.

(22) Li, C.; Yan, H.; Zhao, L. -X.; Zhang, G. -F.; Hu, Z.; Huang, Z.-L.; Zhu, M.-Q. a Trident Dithienylethene-Perylenemonoimide Dyad with Super Fluorescence Switching Speed and Ratio. Nature Commun. 2014, 5, 5709 (1-11).

(23) Kawai, T.; Sasaki, T.; Irie, M. A Photoresponsive Laser Dye Containing Photochromic Dithienylethene Units. Chem. Commun. 2001, 8, 711-712.

(24) He, T.; Tian, H.; Chen, B.; Tu, H.; Müllen, K. Novel Bisthienylethene-Based Photochromic Tetraazaporphyrin with Photoregulating Luminescence. Adv. Mater. 2002, 14, 918-923.

(25) Tan, W.; Li, X.; Zhang, J.; Tian, H. A Photochromic Diarylethene Dyad Based on Perylene Diimide. Dyes Pigm. 2011, 89, 260-265.

(26) Fölling, J.; Polyakova, S.; Belov, V.; van Blaaderen, A.; Bossi, M. L.; Hell, S. W. Synthesis and Characterization of Photoswitchable Fluorescent Silica Nanoparticles. Small, 2008, 4, 134-142. 
(27) Su, J.; Fukaminato, T.; Placial, J. -P.; Onodera, T.; Suzuki, R.; Oikawa, H.; Brosseau, A.; Brisset, F.; Pansu, R.; Nakatani, K.; Métivier, R. Giant Amplification of Photoswitching by a Few Photons in Fluorescent Photochromic Organic Nanoparticles. Angew. Chem. Int. Ed. 2016, 55, 1-6.

(28) Watanabe, K.; Hayasaka, H.; Miyashita, T.; Ueda, K.; Akagi, K. Dynamic Control of Full-Colored Emission and Quenching of Photoresponsive Conjugated Polymers by Photostimuli. Adv. Funct. Mater. 2015, 25, 2794-2806.

(29) Bu, J.; Watanabe, K.; Hayasaka, H.; Akagi, K. Photochemically Colour-Tuneable White Fluorescence Illuminants Consisting of Conjugated Polymer Nanospheres. Nature Commun. 2014, $5,3799(1-7)$.

(30) Li, C.; Hu, Z.; Aldred, M. P.; Zhao, L. -X.; Yan, H.; Zhang, G. -F.; Huang, Z. -L.; Li, A. D. Q.; Zhu, M. -Q. Water-Soluble Polymeric Photoswitching Dyads Impart SuperResolution Lysosome Highlighters. Macromolecules 2014, 47, 8594-8601.

(31) Hayasaka, H.; Tamura, K.; Akagi, K. Dynamic Switching of Linearly Polarized Emission in Liquid-Crystallinity-Embedded Photoresponsive Conjugated Polymers. Macromolecules 2008, $41,2341-2346$.

(32) Uchida, K.; Ishikawa, T.; Takeshita, M.; Irie, M. Thermally Irreversible Photochromic Systems. Reversible Photocyclization of 1,2-Bis(thiazolyl)perfluorocyclopentenes Tetrahedron 1998, 54, $6627-6638$. 
(33) Takami, S.; Kobatake, S.; Kawai, T.; Irie, M. Extraordinarily High Thermal Stability of the Closed-Ring Isomer of 1,2-Bis(5-methyl-2-phenylthiazol-4-yl)perfluorocyclopentene. Chem. Lett. 2003, 32, 892-893.

(34) Nakahama, T.; Kitagawa, D.; Sotome, H.; Ito, S.; Miyasaka, H.; Kobatake, S. Optical Properties and Solvatofluorochromism of Fluorene Derivatives Bearing $S, S$-Dioxidized Thiophene.Photochem. Photobiol. Sci. 2016, 15, 1254-1263.

(35) Nishi, H.; Namari, T.; Kobatake, S. Photochromic Polymers Bearing Various Diarylethene Chromophores as the Pendant: Synthesis, Optical Properties, and Multicolor Photochromism. J. Mater. Chem. 2011, 21, 17249-17258.

(36) Yokoyama, Y.; Kurita, Y. Synthesis and Photoreaction of Photochromic Fulgides. J. Synth. Org. Chem. Jpn. 1991, 49, 364-372.

(37) Parker, C. A.; Rees, W. T. Correction of Fluorescence Spectra and Measurement of Fluorescence Quantum Efficiency. Analyst 1960, 85, 587-600.

(38) Rurack, K.; Spieles, M. Fluorescence Quantum Yields of a Series of Red and Near-Infrared Dyes Emitting at 600-1000 nm. Anal. Chem. 2011, 83, 1232-1242.

(39) Nagasawa, Y.; Itoh, T.; Yasuda, M.; Ishibashi, Y.; Ito, S.; Miyasaka, H. Ultrafast Charge Transfer Process of 9,9'-Bianthryl in Imidazolium Ionic Liquids. J. Phys. Chem. B 2008, 112, 15758-15765. 
(40) Mohamed, A. A.; Jebrael, F. H.; Elsabee, M. Z. Copolymerization of Styrene with $\mathrm{N}$ Arylmaleimides. Macromolecules 1986, 19, 32-37.

(41) Medintz, I.; Hildebrandt, N. FRET-Förster resonance energy transfer from theory to applications; Wiley-Interscience: New York, 2013; pp 25-31. 


\section{Graphical Abstract}

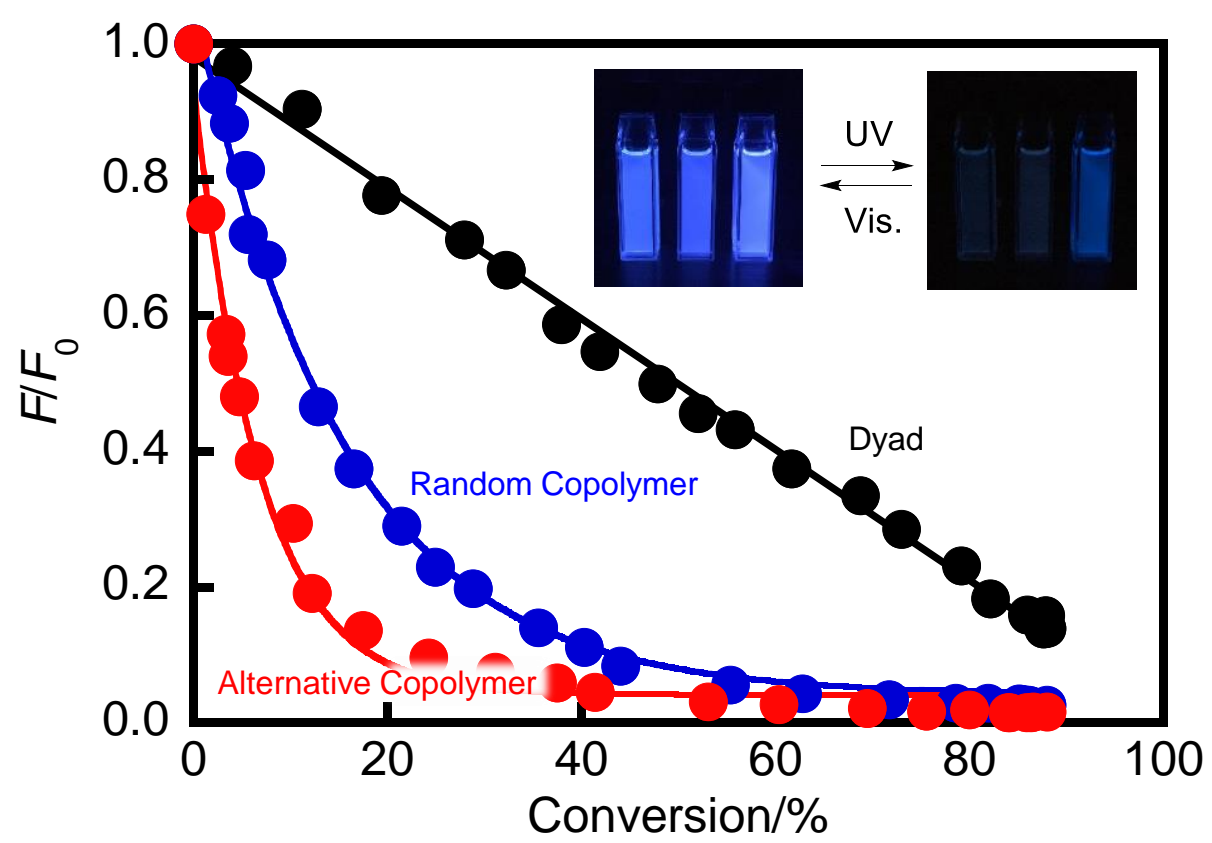

